\title{
La creación de nuevos mitos urbanos: el centro comercial Patio Bullrich
}

\author{
Silvana SASSANO LUIZ \\ Departamento de Geografía Humana \\ Universidad Complutense de Madrid \\ silgeo@yahoo.com
}

Recibido: $14 / 09 / 2012$

Modificado: $11 / 11 / 2012$

Aceptado: $19 / 11 / 2012$

\section{Resumen}

Los centros comerciales son los máximos espacios de consumo simbólico y mercantil de la sociedad capitalista actual. La refuncionalización de ciertos lugares de la ciudad en decadencia o de edificios históricos emblemáticos han devenido en nuevos mitos urbanos, respondiendo a una apropiación simbólica como recuperación y puesta en valor económico en el mercado de ciertas partes de la ciudad. Los valores sociales que están cargados en los edificios emblemáticos o zonas a ser recuperadas por parte de los agentes privados se transforman en recursos recreativos y hasta podríamos afirmar, en renta monopólica.

Palabras clave: globalización, consumo, centros comerciales, Buenos Aires.

Title: The creation of new urban myths: Patio Bullrich Mall

\section{Abstract}

The malls are maximum symbolic and commercial consumption spaces of the actual capitalist society. The re-functioning of certain parts of the city in decline, certain emblematic historic buildings have become in new urban myths, answering a symbolic appropriation as recovery and economic enhancement in the market of certain parts of the city. Social values that are loaded in the emblematic buildings or areas to be "recovered" by private agents become recreational resources and might even say, in monopoly rent.

Keywords: globalization, consumer, shopping centers, Buenos Aires.

\section{Índice}

1. Introducción

2. El centro comercial Patio Bullrich

3. Evolución y características de la zona

4. Una historia de estirpe: La Casa Bullrich

5. Adquisición de los inmuebles

6 . El centro comercial hoy

6.1. Organización interna y oferta comercial

6.2. Percepción del espacio

6.3. Perfil de los visitantes

7. Apropiación de los valores geográficos, históricos y sociales: la creación del mito urbano

8. Conclusiones 


\section{Introducción}

La ciudad y sociedad "posmoderna" se ha visto envuelta en una serie de cambios territoriales, sociales, culturales, tecnológicos, arquitectónicos, basados en los procesos de reestructuración económica global. Desde una mirada espacial, las grandes ciudades son las receptoras principales de estos cambios y son re-creadas por las administraciones locales $y$, sobre todo, por los sectores empresariales privados, engendrando la "ciudad posmoderna de la imagen, de la diferenciación social y del espectáculo" (Amendola 2000: 29).

En esta sociedad postmoderna en la que estamos inmersos, el valor simbólico que adquieren los objetos y los espacios (lugares o no lugares) al ser consumidos es primordial, ya sea para lograr con ello un valor agregado en un negocio inmobiliario por ejemplo, o una diferenciación social entre los propios consumidores. El consumo se convierte en el motor de la vida cotidiana de las familias y los ciudadanos se transforman en consumidores 0 en ciudadanos imperfectos (Santos 1987).

Estamos dentro de un círculo que se retroalimenta, porque la sociedad de consumo reclama y define los bienes y servicios a consumir, y el sistema capitalista genera la "necesidad" de consumo e insatisfacción de los ciudadanos, o mejor dicho, consumidores. El valor del producto, su carga simbólica y el espacio en que es consumido dan lugar a "desigualdades sociales", desigualdades que se han transformado en la sociedad urbana contemporánea globalizada y que debemos analizarlas teniendo en cuenta la "nueva política cultural" que aborda Soja en "Thirdspace" y que retoma en Postmetrópolis: "las diferencias entre las personas son creadas de forma intrínseca, externamente impuestas y culturalmente representadas a través de procesos de formación de identidad cargados políticamente" (Soja 2008: 393).

Las ciudades se han convertido en productos en sí mismas para atraer inversiones y capital, los ciudadanos muestran "imágenes diferenciadas" para identificarse y "no ser excluidos del mundo social al que se pertenece o para adquirir las señas de identidad que permitan acceder al que se quiere pertenecer" (García Ballesteros 1998: 52). Comprar es cada vez más una actividad recreativa, ya que se transforma en el consumo por el consumo mismo.

Los centros comerciales, "îles urbaines de la post-modernité" (Ferreira Freitas 1996), son los lugares más expresivos de esta nueva etapa del capitalismo consumista. "La expresión más visible de esta sociedad de consumo - cultura del consumo (Featherstone 2000)- es la explosión de los grandes centros comerciales" (García Escalona 1997), templos diseñados para estimular a las personas a consumir símbolos, bienes, servicios y lugares. 
La investigación parte de considerar que las transformaciones por las que atraviesa la ciudad de Buenos Aires en los últimos años son al mismo tiempo resultado y en parte contribuyen a sustentar los procesos de integración y globalización económica mundial. En base a los trabajos de López Levi (1999) y Cornejo Portugal (2001, 2007) quienes muy detalladamente analizan las prácticas culturales de apropiación simbólica de los consumidores en el mall, nosotros intentaremos analizar otro aspecto de la apropiación simbólica, que es la generada por los empresarios-agentes privados $\mathrm{y} / \mathrm{o}$ desarrolladores de los centros comerciales, quienes transforman los valores sociales de que están cargados los edificios emblemáticos o zonas a ser recuperadas en recursos recreativos y hasta podríamos afirmar, en renta monopólica, convirtiéndose, al mismo tiempo, en nuevos mitos urbanos, como ha sucedido con el Mercado de Abasto de Buenos Aires (Sassano 2001), el Spinetto shopping, Galerías Pacífico, Galería Güemes, entre otros.

Por mito urbano entendemos el conjunto de creencias (verdaderas o falsas) e imágenes idealizadas y exaltadas que se forman alrededor de un lugar concreto de la ciudad, cargado de significado por su historia y tradición, donde se han vivido acontecimientos históricos significativos para la conformación de la misma, convirtiéndose ese espacio en un modelo o símbolo con características únicas e irrepetibles. En este caso concreto, es gestado por un sector social en beneficio propio: realzan solo aquellos elementos significativos de la historia que puedan dar vida y forma a ese elemento urbano, convirtiéndolo en un símbolo para la ciudad, atractivo y convocante, generando así la necesidad de consumir ese espacio emblemático.

En base a los lineamientos de la geografía urbana y del consumo y de los procesos sociales y económicos que explican la difusión y éxito de los centros comerciales y sus consecuencias territoriales (Escudero Gómez 2008), analizaremos un lugar emblemático de la ciudad de Buenos Aires cargado de historia y de valores sociales que son recuperados por los agentes privados, convertido en un verdadero mito urbano, como es el caso del centro comercial Patio Bullrich (figura 1). 


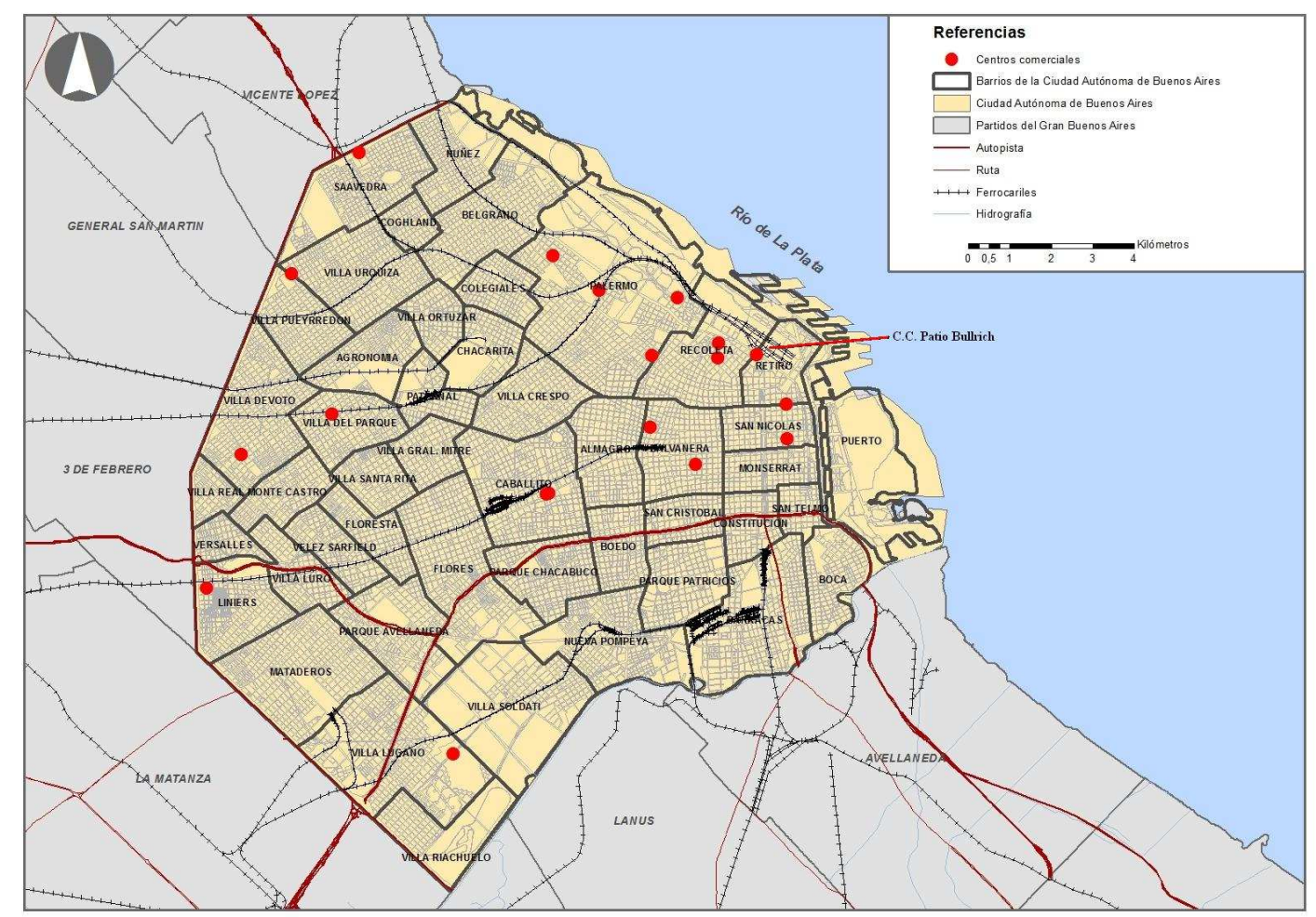

Fuente: Elaboración propia.

Figura 1. Localización de los centros comerciales de la Ciudad Autónoma de Buenos Aires y del Centro Comercial Patio Bullrich.

\section{El centro comercial Patio Bullrich}

"Patio Bullrich shopping center" fue el primer centro comercial de la Ciudad Autónoma de Buenos Aires, inaugurado el 15 de septiembre de 1988. Se localiza en Avenida del Libertador $n^{\circ}$. 750, en la manzana comprendida entre la Avenida Libertador y las calles Posadas, Montevideo y Libertad (figura 2). Al considerar la división política administrativa de la ciudad Autónoma de Buenos Aires, Patio Bullrich quedaría emplazado, por 80 metros, en el barrio de Retiro, ya que el límite entre los barrios de la Recoleta y Retiro pasa por la calle Montevideo. Pero por la propia dinámica, funcionamiento y sobre todo su tradición histórica, se lo considera como parte y símbolo del exclusivo barrio de la Recoleta. 


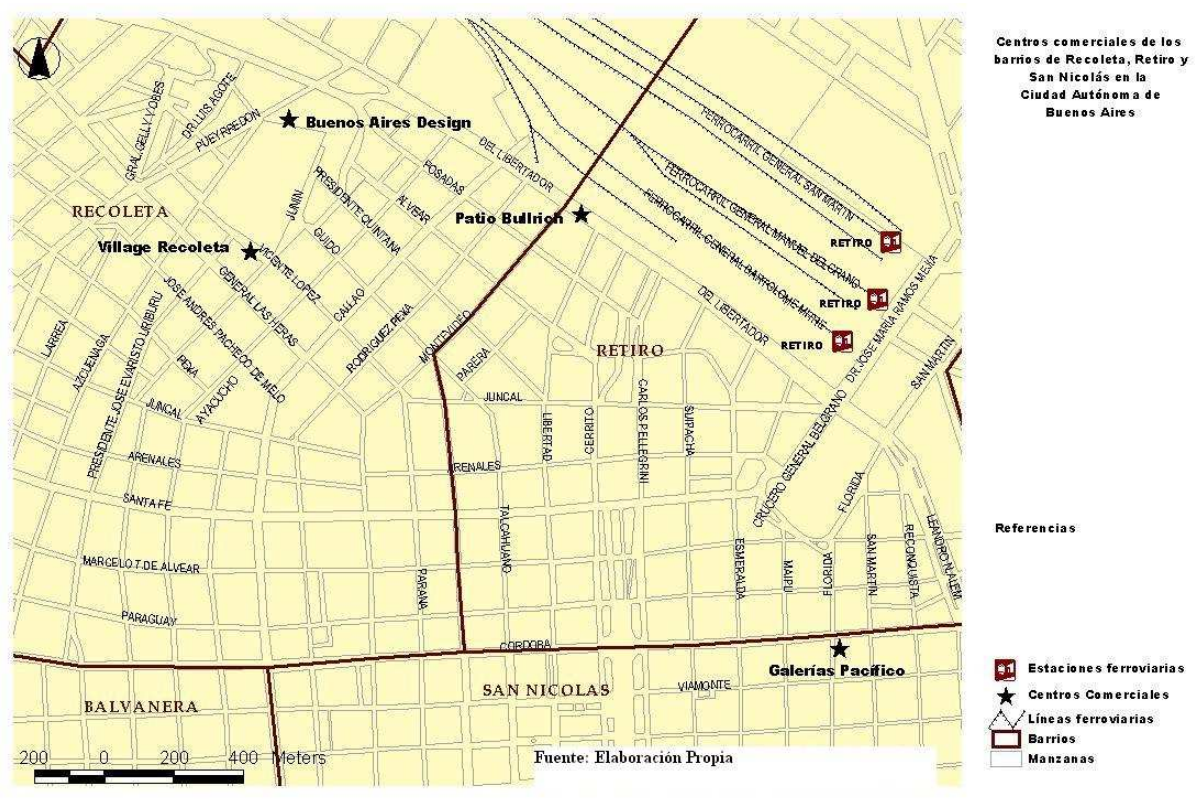

Fuente: Elaboración propia.

Figura 2. Localización de Patio Bullrich.

Su ubicación es privilegiada, localizándose en una de las zonas más tradicionales y distinguidas de la ciudad, de alto poder adquisitivo, densamente poblada, rodeada de prestigiosas residencias, embajadas, instituciones culturales, hoteles internacionales ${ }^{1}$ y a menos de 1000 metros del centro de decisión económico y financiero de la ciudad (figura 3 ).

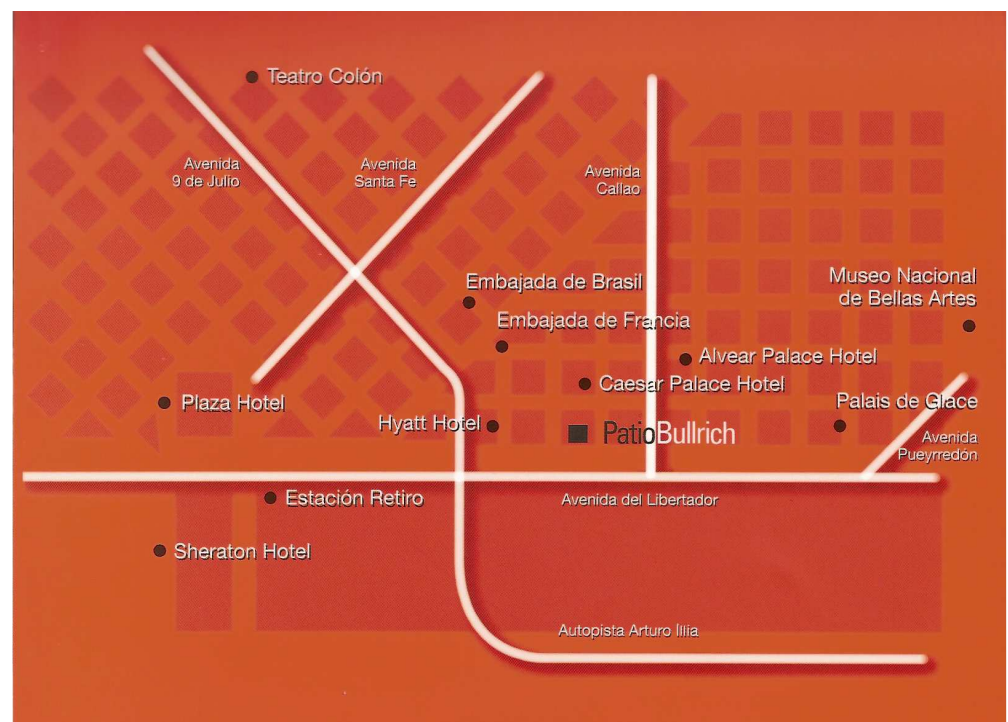

Fuente: Patio Bullrich 2001.

Figura 3. Ubicación urbana privilegiada de Patio Bullrich.

${ }^{1}$ Obras arquitectónicas de estilo francés, fundamentalmente de finales del siglo XIX y principios del $X X$, años en que el país vivía momentos de gran prosperidad y crecimiento económico. 
El barrio de la Recoleta también cuenta con las dos avenidas más sofisticadas, cotizadas y de glamour de la ciudad como son las Avenidas Alvear y Quintana. En su recorrido albergan muchos palacios, embajadas y marcas globales como Ralph Laurent, Louis Vuitton, Peter Kent, Versace, en ropa y accesorios; joyerías como Vicente Hernández, Santarelli; galerías de arte como Alvear (expositores de arte plástico y orfebrería nacional), Alvear Art Gallery, Colección Alvear de Zubarán Escada; perfumerías como Rochas, Nina Ricci, entre otras.

\section{Evolución y características de la zona}

El actual barrio de la Recoleta adquiere su nombre por el Convento de la Orden de los Franciscanos Recoletos y la Iglesia del Pilar, inaugurados en 1732. Hasta la propagación de la epidemia de fiebre amarilla en 1871, fue un gran espacio vacío (campo abierto y huertas), momento en que los residentes de mayores recursos económicos (políticos, profesionales, banqueros, comerciantes, estancieros, etc.) se trasladan desde la zona sur de la ciudad, por donde se propagaba la enfermedad, a las zonas altas "vacías" como fueron los actuales barrios de Retiro, Recoleta, Norte, Devoto, Belgrano, Flores, etc. Las huertas dejan paso así a las grandes mansiones y palacetes diseñados por arquitectos extranjeros. "Estos grandes edificios adquirieron el papel de hoteles por la fastuosidad de su exterior, la extensión del terreno que abarcan, el número y la diversidad de sus apartamentos y la riqueza de su decoración [...]" (Cutolo 1996: 829). Estas residencias convierten al barrio de la Recoleta en el más lujoso de la ciudad, "[...] iniciándose el desarrollo del barrio norte, como área de élite" (Scobie 1977: 45).

\section{Una historia de estirpe: La Casa Bullrich}

La familia Bullrich procedía de Hamburgo, Alemania. Don Augusto Adolfo Bullrich, nacido en Berlín en 1802, se instala en Argentina y comienza su actividad con un negocio de productos importados. Su hijo mayor Adolfo Jorge Bullrich, nació en Buenos Aires en 1833 y a los ocho años de edad su padre lo envía a Alemania a estudiar. De regreso en Buenos Aires consolida su posición económica y social llegando a ser Intendente de la Ciudad de Buenos Aires entre 1898 y 1902, durante el gobierno del Presidente Julio A. Roca, uno de los impulsores de importantes mejoras urbanas (tranvía eléctrico, iluminación eléctrica, pavimentación de calles, embellecimiento de parques y del Jardín Zoológico, etc.) (La Prensa, 5/04/1967; Mujica Laínez s.d.). En 1867 funda la casa de subastas ${ }^{2}$ Bullrich. Durante

${ }^{2}$ En Argentina se utiliza el término remate en lugar de subasta. Por ello se conoce a esta casa con el nombre de "Casa de Remates Bullrich". 
más de un siglo, la tradicional "Casa Bullrich" realizó las principales subastas de la ciudad: grandes campeones de la ganadería, obras de arte, alhajas, esculturas, barcos, carrozas, mobiliario firmado, armas, pertenecientes a personajes famosos o de alto poder adquisitivo de la época (La Prensa, 5/04/1967) ${ }^{3}$. La primera Casa de subastas Bullrich estaba situada en la Recova Nueva, calle de la Victoria 90, entre Defensa y Bolívar. Pero la continua expansión de la actividad obliga a estos empresarios a trasladarse a la calle Leandro N. Alem 950 (hoy Avenida del Libertado 750), a un edificio de estilo neoclásico inglés diseñado por el arquitecto Waldorp. En la década de los sesenta adquieren el solar de la calle Posadas 1245, uniéndolo al anterior, logrando así salida hacia la misma.

Sobre la puerta principal del edificio (avenida Libertador), se encontraban salas de estar, salones destinados a la venta de muebles, la biblioteca de la Casa Bullrich, y en la parte posterior, hasta la mitad de la manzana, el patio de subastas propiamente dicho, ocupando casi dos tercios del terreno (Volpe 2002) (figura 7). Este patio de subastas era una estructura de hierro y vidrio, arquitectura característica de fines del siglo XIX y principios del XX utilizada en los mercados de abastos.

Diez años más tarde, la Casa de subastas Bullrich cierra sus puertas, comprando el edificio los ingenieros Maccarone en 1982.

\section{Adquisición de los inmuebles}

Los ingenieros Maccarone adquieren el edificio ubicado sobre la avenida Libertador con el fin de construir allí un supermercado y una torre de viviendas. Los vecinos se oponen y la Municipalidad de la ciudad de Buenos Aires finalmente rechaza el proyecto por "cuestiones técnicas". La idea se presenta al estudio de arquitectura Juan Carlos López y Asociados, quienes deciden comprar a la familia Bullrich también el predio con salida a la calle Posadas ${ }^{4}$. Ambos edificios estaban cerrados y vacíos, resolviendo finalmente rehabilitarlos para abrir el primer centro comercial de la ciudad de Buenos Aires. La obra fue realizada en 1988 por la empresa ingenieros Maccarone S. A., proyectada por el estudio de arquitectura

\footnotetext{
3 "Por Patio Bullrich, no solo [pasaron] las riquezas sino también el refinamiento de las mejores cunas argentinas. [...] Pero también pasó por allí la más selecta sociedad porteña e ilustres visitantes, Eduardo VII, Príncipe de Gales. Allí funcionó una suerte de concilio permanente de la clase ganadera y de la cultura bonaerense" (Patio Bullrich 1988).

${ }^{4}$ Se lograba así "[...] una situación que desde el punto de vista potencial de desarrollo comercial era mucho más rica en tanto que empezaba a vincular dos calles, una de tráfico rápido y más de borde como es Libertador, y otra Posadas con otra situación mas urbana de actividades vecinales. En ese entonces la zona era puramente residencial, fuera de algún bar o confitería" (Volpe 2007).
} 
Juan Carlos López y Asociados y comercializada por Aranalfe S. A. y Fibesa S. A.

Patio Bullrich Shopping surge, por tanto, de la remodelación y refuncionalización de los dos edificios de la antigua Casa Bullrich: el primero ubicado en avenida Libertador 750, con una fachada de estilo neoclásico y una arquería en planta baja que se corresponde con aberturas de ventanas de forma rectangular en el piso superior (Guía de la Arquitectura de Buenos Aires 1992), el patio de remates propiamente dicho, y el segundo, un edificio de hormigón ubicado en la parte posterior del anterior, con entrada por la calle Posadas 1245. Su fachada también está precedida por una recova de tres arcadas.

El proceso técnico de conexión y remodelación de las dos parcelas fue complejo. En el viejo patio de remates, sólo existía la planta baja (figura 7) y por tanto la estructura fue modificada: se crearon dos nuevas plantas con una distribución lineal extendiéndose desde el sector Libertador al sector Posadas, y, en cada extremo, por el levantamiento en altura que se hizo en cada fachada, se generaron nuevas plantas (una sobre el sector Libertador y dos sobre el sector Posadas) (Volpe 2002).

Otra dificultad a salvar fueron los 3,4 metros de desnivel existentes entre la calle Posadas y la avenida del Libertador. Para aprovecharlo, la entrada por Libertador tiene unas pequeñas escaleras de estilo neoclásico que se dirigen unas hacia el nivel Posadas y las otras hacia el nivel Libertador, por lo que el centro comercial "[...] tiene prácticamente dos plantas bajas, una por Libertador y otra por Posadas" (Volpe 2002). En el interior se construyó una rotonda permitiendo la unión de ambos predios y resolviendo el desnivel existente (figura 4).

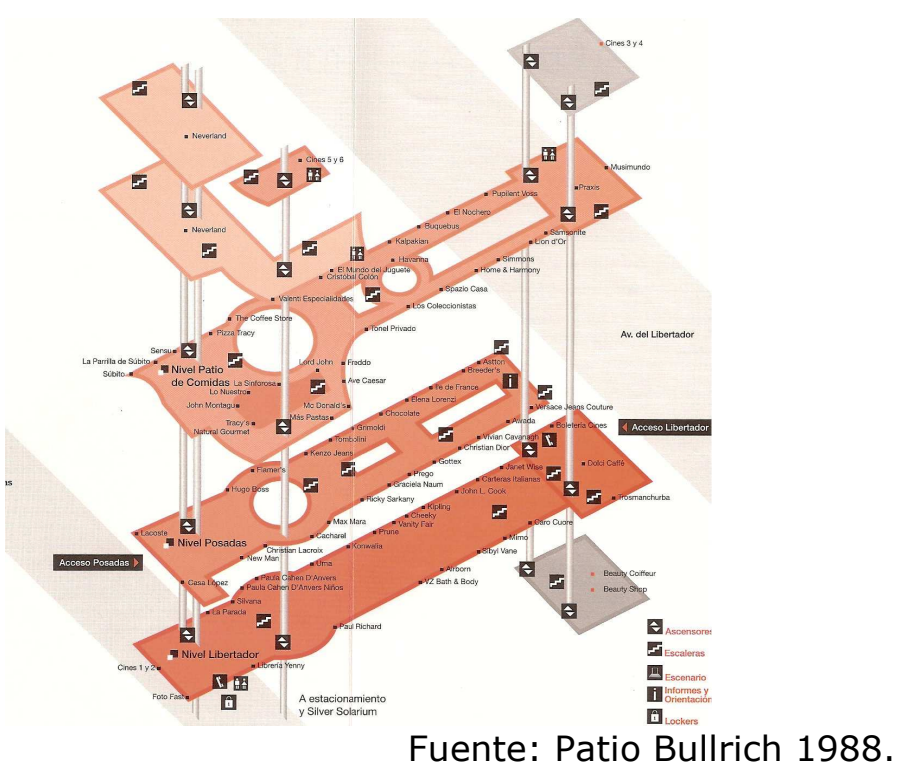

Figura 4. Plano distribución interna del centro comercial Patio Bullrich. 
Las fachadas de ambos edificios han permanecido semiintactas. A la de avenida del Libertador se le ha agregado, en la parte superior, una estructura acristalada en tono oscuro con una amplia cornisa para lograr una altura más. Y la fachada del viejo edificio de la calle Posadas se ha reformulado, intercalándose planos de cristal oscuro, el mismo que en la fachada de Libertador (figura 5). En 1995 los propietarios del centro comercial adquieren el predio contiguo sobre la calle Posadas, de ochocientos metros cuadrados, unificando las fachadas mediante una cornisa/cenefa (Arquis 1996) y un muro acristalado transparente con planos opacos que permiten ver, a modo de escaparate, las actividades del shopping center. Se amplía el sector de hostelería y recreación y se generan dos plantas superiores totalmente integradas al espacio preexistente, donde hoy funciona el área de entretenimientos para niños de la empresa Neverland y dos salas de cine (La Nación, 14/06/1995). Esta ampliación se hizo para brindar una mayor variedad a la oferta comercial y ampliar el segmento de edades de los consumidores (entre 20 y 65 años), sobre todo para atraer a un público más joven.
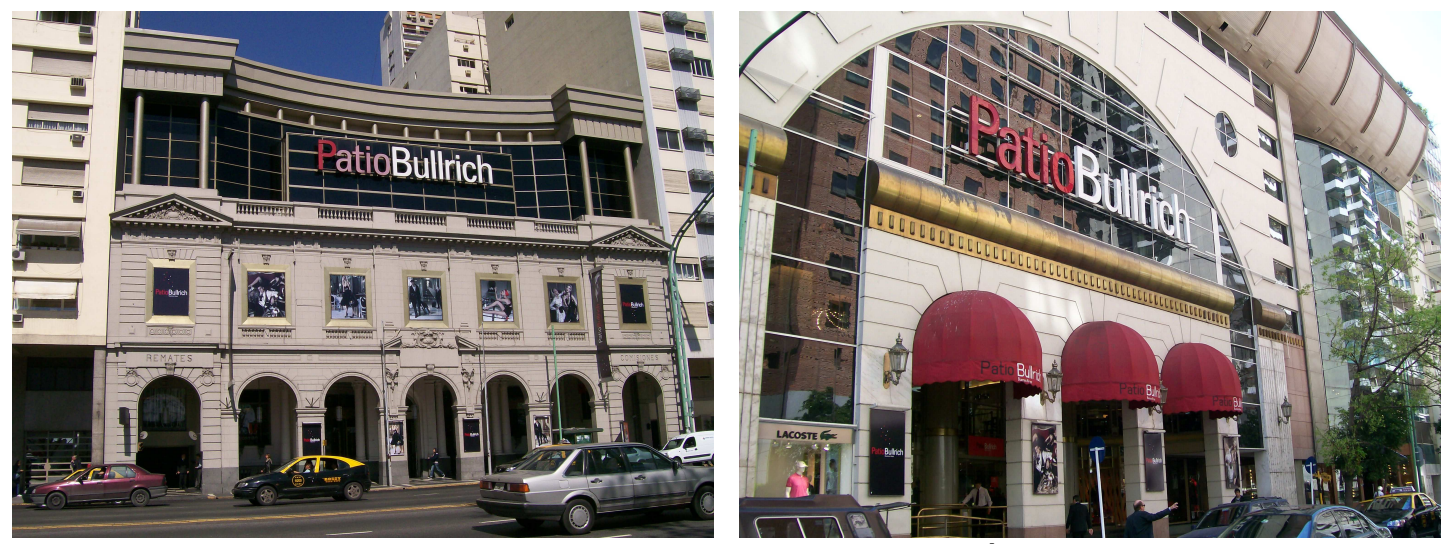

Fuente: Fotografías de Silvana Sassano Luiz.

Figura 5. Fachada Av. Libertador (izda.) y fachada calle Posadas (dcha.).

Los elementos decorativos originales preservados son el gran reloj que presidía el antiguo patio de subastas Bullrich (aunque ha variado su ubicación a lo largo de los años); las esculturas que reproducen las cabezas de ganado, que fueron trasladadas y modificados sus apoyos; la estructura de hierro original solo se puede observar en el techo y las columnas ubicadas encima de la última planta, quedando esas mismas columnas pero en las plantas inferiores recubiertas por mármoles, cemento o formando parte de las propias paredes de los locales comerciales (figura 6). 

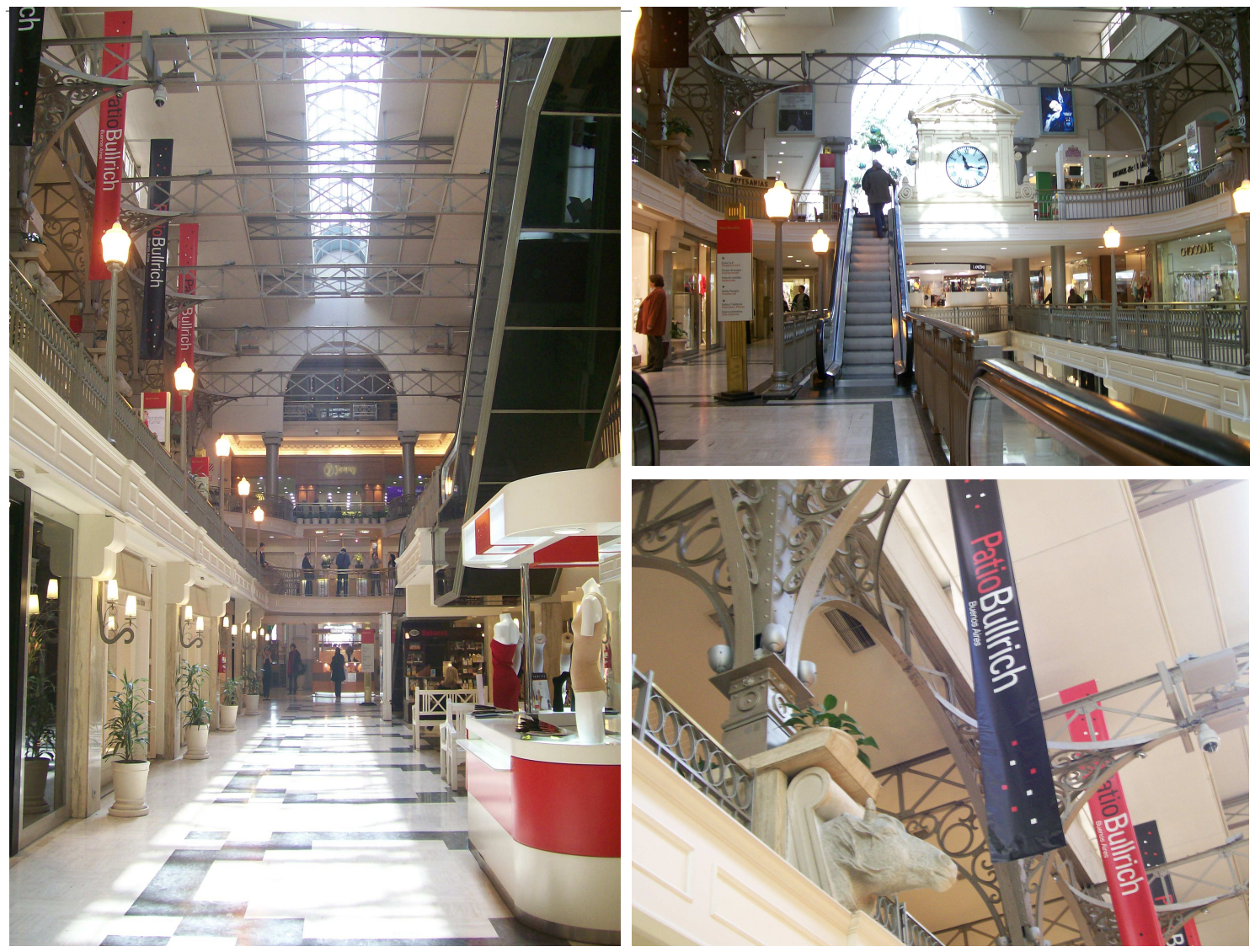

Fuente: Fotografías de Silvana Sassano Luiz.

Figura 6. Elementos decorativos originales preservados.

En 1990, Patio Bullrich shopping center obtuvo el premio Design and Development Award for Innovative Design and Construction of a New Center, otorgado por el International Council of Shopping Centers y, en 1992, la mención especial del International Iron and Steel Institute, por el innovador tratamiento arquitectónico de la estructura de hierro, todo un reconocimiento a nivel mundial teniendo en cuenta que Argentina se incorpora tardíamente en la implantación de centros comerciales (Patio Bullrich 1990b, 2001).
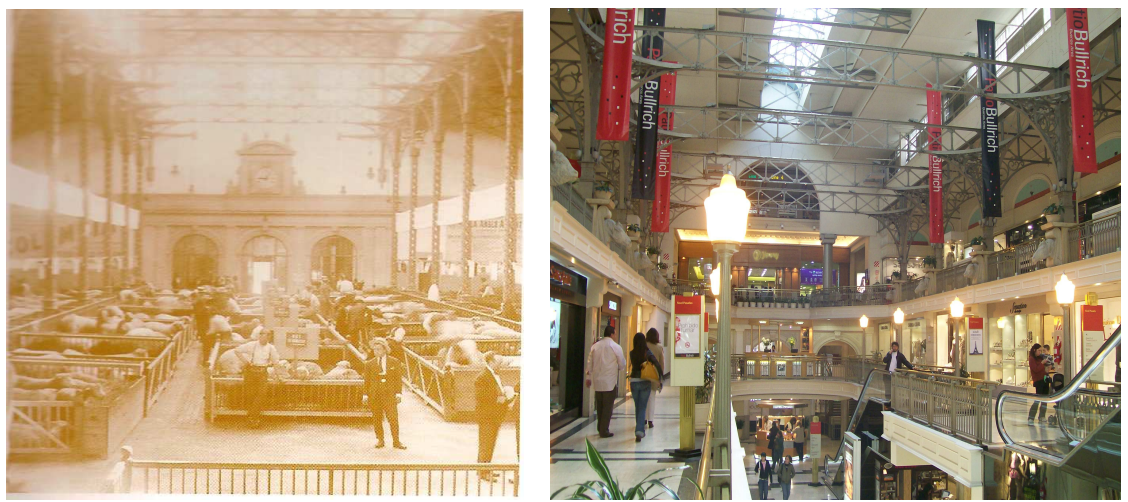

Fuente: Tríptico Patio Bullrich (izda.) y Silvana Sassano Luiz (dcha.).

Figura 7. El antes y el después. 


\section{El centro comercial hoy}

El grupo Maccarone vende Patio Bullrich al grupo IRSA, a través de su empresa subsidiaria Alto Palermo S. A. (APSA), el 16 de julio de 1988, firmándose la escritura definitiva el 1 de octubre de ese mismo año (Alto Palermo 1998), constituyéndose IRSA en la empresa que prácticamente posee todos los centros comerciales en la ciudad Autónoma de Buenos Aires.

Patio Bullrich tiene una superficie cubierta de $28.982,61 \mathrm{~m}^{2}$. De ésta, corresponden al aparcamiento $4.825 \mathrm{~m}^{2}$ con 215 plazas interiores. La superficie bruta alquilable (SBL) es de $11.615,36 \mathrm{~m}^{2}$, de los que corresponden $1.444,77 \mathrm{~m}^{2}$ al área de juegos infantiles, $1.601,88 \mathrm{~m}^{2}$ a cines y $8.568,71 \mathrm{~m}^{2}$ a locales comerciales. El número de locales asciende a ciento nueve, incluyendo los destinados a restauración. Todos los locales son propiedad del centro comercial. Posee también una amplia zona de restauración con capacidad para ochocientas personas. La afluencia mensual de público es de 470.000 personas (CASC 2012).

Está ubicado en una zona de fácil acceso vehicular, por vías rápidas como las avenidas Libertador, la autopista Arturo Illia, desde el norte de la ciudad, y la Avenida 9 de Julio, desde el sur y el oeste. Se accede a la zona por siete líneas de autobuses urbanos y, a 500 metros, se encuentran la terminal de tren de Retiro. Pero el grueso de los visitantes llega en vehículo privado, caminando desde los hoteles próximos o viviendas cercanas o bien mediante un servicio de transporte privado sin cargo, remis ${ }^{5}$, que ofrece el propio centro comercial a los turistas desde el hotel donde están alojados.

El horario de apertura de los locales comerciales es de lunes a domingo de 10 a 21 horas; el patio de comidas, de domingo a jueves de 10 a 24 horas y viernes y sábados de 10 a 1:00 horas. El servicio de aparcamiento es de pago.

\subsection{Organización interna y oferta comercial}

La distribución se realiza a partir de una calle central que tiene acceso por Avenida Libertador y calle Posadas (figura 4). Está distribuido en tres niveles con locales comerciales en los laterales, sobre las medianeras, y algunos stands ubicados en los pasillos centrales y cafeterías. Entrando por Avenida Libertador encontramos un café-restaurante y las boleterías de las salas de cine hacia la derecha. Desde aquí parten unas escaleras de obra que llevan al subsuelo, a las tiendas de belleza y estética "Beauty Coiffeur" y Rouge. También unas escaleras de obra hacia la planta superior (nivel Posadas).

${ }^{5}$ Remis es un coche con conductor que se alquila para hacer trayectos cortos. Servicio similar al taxi. 
Al nivel Posadas se accede exteriormente desde la calle Posadas e interiormente por escaleras mecánicas y ascensores dispuestos en cada extremo de la calle central. Esta planta es de recorrido circular ya que tiene una abertura central y desde sus balcones puede verse el resto de plantas. Una rotonda de amplias dimensiones se abre casi llegando al sector Posadas.

En el nivel superior, llamado "patio de comidas" (sector Libertador) se dispone la librería Yenny y frente a ella, la cafetería Kaffa Expreso, con sillones de cuero blanco y mesas de madera marrón. Hacia un lateral, una escalera de obra y ascensores acceden a la entreplanta donde se encuentran los cines 3 y 4 (en el momento de la inauguración del centro comercial, había un salón de fiestas). El techo de este sector está cubierto por un amplio Vitro.

Las marcas de alto nivel internacional y nacional responden al tipo de clientela que consume el centro comercial. El mayor porcentaje está destinado a la moda femenina, con 35 locales (Akiabara, Carolina Herrera, El Nochero, Hugo Boss, Lacoste, La Martina, Zara, etc.), y masculina, con 16 locales (Etiqueta Negra, Lacoste, Liguria, La Martina, etc.); cuatro tiendas de moda infantil (Grisino, Cheeky), cinco joyerías, como Swarovski, Tiffany \& Co., Omega, Homero Rolex, etc., locales de artículos regionales argentinos (destinados al turismo), siete tiendas de zapatos y bolsos (Prune, Ricky Sarkani, Mishka), Stand de la Fundación del Teatro Colón, dos ópticas, siete tiendas de estética y belleza (Rouge, VZ, Bath \& Body, Seacret). No hay servicios bancarios, solo un cajero Banelco.

El patio de comidas es amplio y ocupa parte de la última planta, desde la rotonda hasta la calle Posadas. Sobre el frente se ubican mesas aprovechando la visión de la calle que se tiene con el gran muro acristalado que forma la fachada de esta calle. Los locales gastronómicos no desentonan con el estilo del diseño moderno del resto de locales comerciales. Hay restaurantes y cafeterías de alto nivel, con servicio de mesas (camareros) y cada local tiene su "propio sector" diferenciado por el diseño del mobiliario. Desde el patio de comidas se accede a dos entreplantas superiores (sector Posadas), por escaleras mecánicas, escaleras metálicas amplias y ascensores, donde se accede a los cines 5 y 6 y al sector de entretenimiento infantil (Neverland ${ }^{6}$, un carrusel, juegos electrónicos, etc.).

\subsection{Percepción del espacio}

La calidad del mobiliario y de los acabados de arquitectura, los detalles de diseño, los locales comerciales, cines, aseos de todo el centro comercial, están muy cuidados y destinados a un tipo de público de mayor poder adquisitivo, conservador, de mayor edad,

\footnotetext{
${ }^{6}$ Empresa dedicada a los juegos de entretenimiento infantiles.
} 
perteneciente a un grupo social determinado (exclusivo, de "pedigri"). El diseño general interno en todos sus detalles es sobrio y elegante y se mantiene en todas las plantas.

La solución espacial permite tener una visión de conjunto, tanto desde los extremos del centro comercial como durante el recorrido de la zona central. La luz natural que penetra por los techos transparentes y el diseño en la altura otorgan una sensación de amplitud, aún más de la que realmente tiene. La unión entre los dos viejos edificios, de muy distintas funciones en sus orígenes, ha sido perfectamente salvada. Sólo se diferencia la cubierta, que no tiene las mismas características en todo el centro comercial, ya que se ha mantenido el techo de hierro y vidrio del viejo Patio de subastas, y al resto se ha incorporado la cúpula vidriada de la rotonda central y las galerías centrales transparentes del edificio de Posadas (figura 8).

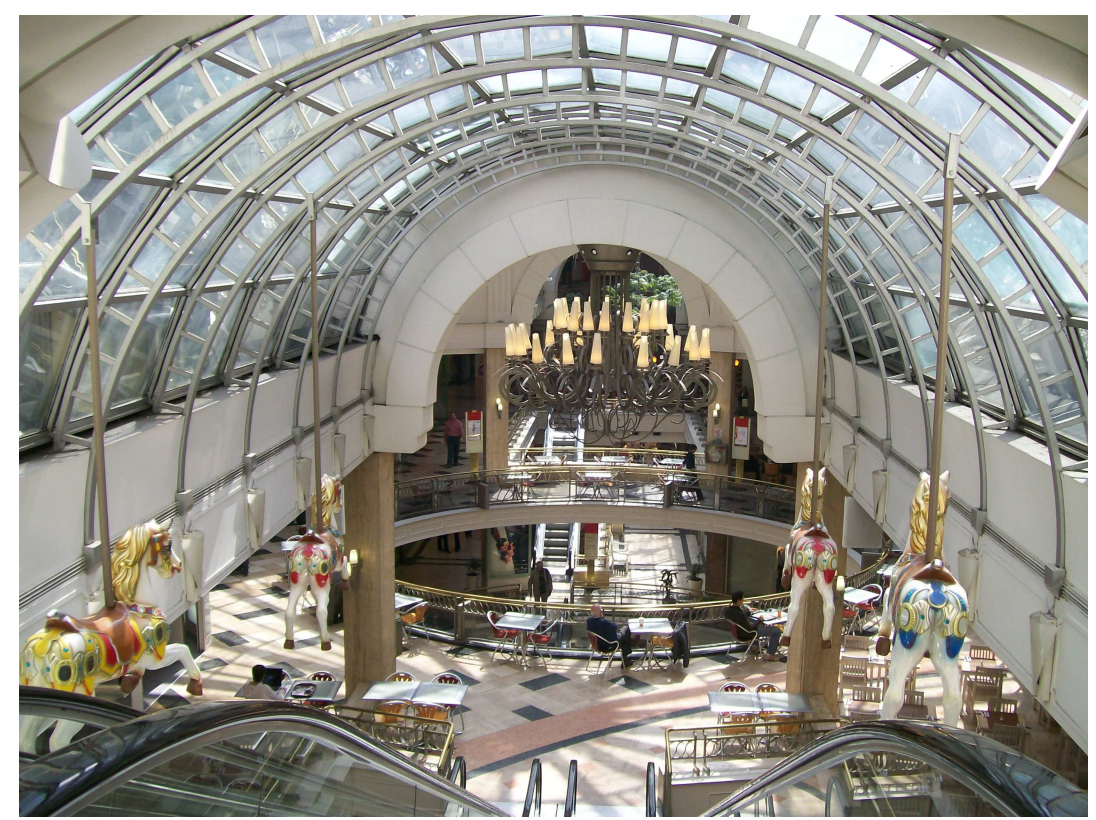

Fuente: Fotografía de Silvana Sassano Luiz.

Figura 8. Rotonda que actúa de nexo entre los dos antiguos edificios.

Internamente los accesos entre las plantas se realizan por medio de ascensores y escaleras de obra, metálicas (ubicadas sobre el sector Posadas) y mecánicas, revestidas con espejos oscuros. No hay ascensores panorámicos ni vidriados. Los suelos son de mármol travertino beige combinado con granito verde peacock (Guía de la Arquitectura de Buenos Aires 1992). Las paredes están revestidas en este mismo mármol al igual que las columnas; algunas, en la zona de restauración, son de bronce. El logo "Patio Bullrich" es rojo y negro. Los balcones que asoman al patio central tienen barandillas de bronce y hierro pintado.

Los elementos de la naturaleza que se encuentran son la abundante entrada de luz natural y algunas jardineras con plantas 
verdes aisladas sobre los laterales de los pasillos y en las zonas de mayor entrada de luz (rotonda y galería central) colgando del techo.

La Directora del área comercial de Patio Bullrich nos comentaba que "[...] la iluminación no es óptima porque se utiliza luz cálida, que es mas amarillenta y no luz blanca, pero eso ayuda a resaltar el estilo conservador y antiguo del lugar [...]". Queriendo asemejarse a las calles de la ciudad, en el nivel Posadas se distribuyen sobre la barandilla de los balcones, unas farolas estilo antiguo, con luz tenue amarillenta. La música es suave y no hay ruidos de fondo. "La gente identifica al shopping también porque tiene un olor particular, y esto es porque se coloca en los conductos de ventilación un perfume de ambientes" (González 2001).

La descripción de estos detalles de diseño interior, ambientación, música, acabados, programas culturales, demuestran cómo se va formando el "mito urbano", como los desarrolladores utilizan también estas estrategias para engrandecer y reforzar elementos de la historia y valores sociales que están cargados en el edificio.

\subsection{Perfil de los visitantes}

El público que consume el centro comercial Patio Bullrich pertenece a un segmento socioeconómico muy elevado: un $70 \%$ son mujeres, frente a un $30 \%$ de hombres. La edad promedio es de 41 años; los mayores de 44 años representan el $48 \%$ de los visitantes, entre los 25 y 44 años el $37 \%$, los jóvenes entre 18 y 24 años el $12 \%$ y los adolescentes de entre 13 y 17 años solo el $3 \%$. El nivel socioeconómico al que pertenecen estos grupos, en un $50 \%$ se corresponde con el $A B C 1$ (nivel socio económico alto), en un $47 \%$ al C2 y C3, nivel alto-medio y solo un $4 \%$ al D1, nivel socioeconómico bajo. El $85 \%$ posee tarjeta de crédito y permanece en el shopping un promedio de 70 minutos por visitante (Patio Bullrich 2010) ${ }^{7}$.

El radio de concentración de donde provienen los clientes son los barrios de Recoleta, Barrio Norte y Retiro, y luego zona Centro, Tribunales, Palermo, Belgrano, Núñez. Esto se evidencia también en el tiempo de traslado de los visitantes al shopping: el $41 \%$ tarda menos de 5 minutos, el $19 \%$ entre 6 y 10 minutos, otro $19 \%$ entre 11 y 20 minutos, y un $21 \%$ más de 20 minutos (Patio Bullrich 2010).

"El público es muy 'conservador' y está destinado al estilo conservador de su público [...]. Cuando se instaló una de las marcas de ropa para un público más joven, hubo quejas de los clientes; lo

\footnotetext{
${ }^{7}$ Aunque tuvimos entrevistas con los responsables del propio centro comercial y del grupo económico que lo desarrolla, APSA, por norma de la empresa, está prohibido hacer encuestas dentro del centro comercial y sacar fotografías a los locales comerciales. Por tanto, la información estadística disponible fue facilitada propio centro comercial.
} 
mismo pasó con McDonald's" (González 2001). "Tiene un perfil dirigido a un cierto estrato etario, es decir, no es para la juventud Patio Bullrich. [...] Y por otro lado explota la oferta turística que ofrecen los hoteles de lujo que se establecieron a su alrededor" (Volpe 2007).

Los centros comerciales tienen como objetivo único incitar al consumo poniendo bajo control estímulos, pulsiones, deseos, comportamientos, como es el caso de la luz o la música en el Patio Bullrich. Como señala Amendola (2000) en un centro comercial todo está estudiado para que el cliente se sienta espectador, parte del espectáculo y consumidor.

Otro sector al que intentan captar los shopping centers son los turistas. Luego de la crisis argentina del 2001, la actividad turística se reactivó con mayor fuerza en el país y aún más en la ciudad de Buenos Aires. Patio Bullrich, al estar ubicado en una zona céntrica, cercano a los hoteles de alta categoría y al ser un emblema históricocultural que encierra parte de la tradición porteña de principios de siglo $X X$, es un lugar ofertado dentro del circuito turístico de la ciudad. Se realizan actividades específicas para estos clientes, como espectáculos de tango, tarjetas de descuentos ofrecidas en los hoteles de la zona y traslado gratuito desde el hotel hasta el centro comercial.

Las actividades dispuestas por el centro comercial han ido variando con el tiempo. Desde hace siete años consecutivos se organizan los "exclusivos torneos de Patio Bullrich Golf Tour" para los clientes del centro comercial, jugándose la final en el LlaoLlao Hotel Resort \& Spa, Patagonia argentina (San Carlos de Bariloche). "Este torneo de Golf está especialmente orientado a clientes del Patio, el cual en su primer año contó con más de 1000 participantes" (Shopping Bullrich s.d.).

Hay que resaltar que es el único centro comercial que tiene un stand de la Fundación Teatro Colón, espacio donado por el propio centro para que su tienda continúe ofreciendo al público "a total beneficio de su misión de apoyo al Teatro: regalos, souvenirs, accesorios y libros centrados en el Colón y sus manifestaciones artísticas: la ópera, el ballet y la música clásica" (Fundación Teatro Colón s.d.).

Otra oferta cultural es la exposición permanente "Los Coleccionistas, pintura argentina", dirigida por el artista plástico Daniel Gallet, donde participan artistas de renombre internacional. (Gallet 2010). Conciertos de música clásica han sido otras de las actividades programadas.

El tipo de actividades deportivas y culturales muestra la exclusividad del sector socioeconómico hacia el que van dirigidas las mismas. 


\section{Apropiación de los valores geográficos, históricos y sociales: la creación del mito urbano}

Las estrategias comerciales basadas en la nostalgia y la recuperación del pasado junto a la arquitectura hecha de citas y de revivals, tienden a anular en la escena urbana la distinción entre ayer y hoy, entre el presente y el pasado. "Los medias actúan sobre el sentido del espacio y de la distancia, por lo cual el sujeto espectador tiende a asistir a un espectáculo - del cual se siente parte viva- donde todo, en unidad de tiempo y lugar, se desarrolla simultáneamente y en el mismo sitio" (Amendola 2000: 180).

El discurso general y la exaltación de ciertos valores por la prensa nacional y por los propios desarrolladores, son esenciales a la hora de crear los mitos urbanos. Al analizar los diversos artículos publicados confirmamos este extremo. Por ejemplo, el periódico La Razón decía: "El patrimonio histórico ha sido salvado, especialmente por la buena disposición de la Municipalidad capitalina, cuyo jefe es Facundo Suárez Lastra [...]" (La Razón 16/09/1988: 6). El diario La Nación remarcaba que con esta inauguración comenzaba el auge de un fenómeno "[...] que tiende a cambiar los hábitos de compra de los argentinos" (La Nación 14/09/1988, 16/09/1988). Aún se mantiene, en ciertos sectores sociales de Argentina, la mirada hacia afuera, hacia lo europeo como superior: "Es europeo, no parece un shopping de la Argentina", comentario destacado entre el público asistente a la inauguración de Patio Bullrich (La Nación Revista 29/09/1988).

Se hace un constante paralelismo entre lo que representó la antigua Casa Bullrich para el desarrollo del país y lo que representa en la actualidad el nuevo Patio Bullrich: "[...] contribuir a instalar a Buenos Aires al nivel de las grandes capitales del mundo" (La Nación 17/09/1988). La gerente del centro comercial en el momento de la apertura afirmaba: "hemos partido de algo que ya existía, adaptándolo e integrándolo en forma armónica a la nueva estructura, porque creemos que algo que ha pertenecido a la comunidad tiene su historia, y debe seguir perteneciéndole" (La Nación 24/08/1988).

Los anuncios publicitarios de la prensa escrita en los años de su apertura, mostraban dos imágenes: una, con la antigua fachada de la Casa de subastas Bullrich y el texto "Este edificio fue un lugar de encuentro..." y otra imagen con la nueva fachada ya rehabilitada y el texto: "A partir de hoy vuelve a serlo". "Habrá muchos shopping centers, pero un solo Patio Bullrich", remarcándose sus características de único y de exclusivo, destinado a un sector social de alto poder adquisitivo, como dice textualmente: "por una cuestión de pedigrí, haciendo un paralelismo, no literal, entre las mejores razas de animales y los representantes de las mejores familias que por allí pasaron y hacia las que ahora está orientado el nuevo centro comercial (La Nación 16/09/1988). 
La observación del discurso de los desarrolladores y de la prensa escrita son primordiales y tienen un gran peso en la formación del mito, ya que realzan los valores sociales y simbólicos cargados en el propio edificio, trayéndolos de la historia a la vida actual. Por un lado es la rehabilitación de un viejo edificio emblemático y por otro la recuperación de los testimonios y tradiciones del pasado, del estilo y categoría de la sociedad que frecuentó este espacio geográfico y arquitectónico de la ciudad. Por ejemplo, "De una estirpe tradicional que abrió sus puertas en 1867, el Patio Bullrich Shopping Center fue la continuación lógica. Hoy Patio Bullrich perpetúa ese estilo, devolviendo a la comunidad, remozado, un lugar que siempre le perteneció"; "[...] preservó todo aquello con lo que había nacido: los valores originales del noble edificio y su arquitectura neoclásica" (Patio Bullrich 1990b, 2001).

"La historia es usada para roles serviles y se convierte en una decoración banal: preservacionismo fetichista de algunos muros como cáscaras" (Sarlo 2001: 19). La historia se convierte en un detalle importante más.

El centro comercial en general se recrea como un espacio nostálgico y estimulante para atraer a turistas y consumidores. En el caso del Abasto Shopping (Sassano 2001) es más representativo en cuanto a la recreación de espacio nostálgico como añoranza de lo que fue y no volverá..., en cambio, en Patio Bullrich se recrea el espacio nostálgico pero como algo estimulante, pretende volver a recuperar un espacio -escenografía- que pertenecía al mismo sector que hoy la va a frecuentar-disfrutar-apropiar, aunque solo sea en el imaginario. "La incorporación y la utilización del pasado son un aspecto constante en la ciudad moderna -postmoderna- siempre suspendida entre realismo y utopía, entre mercancía y sueño, entre praxis e imaginario" (Amendola 2000: 233).

Se resalta también como slogan y como marca registrada la recuperación para la ciudad y para el bien público de este edificio histórico, de los pocos elementos que han sobrevivido, como por ejemplo, la estructura de hierro del patio de remates, las esculturas de cabezas de ganado y la muestra de imágenes antiguas y actuales de la estructura del viejo reloj que presidía el patio, como una forma de demostrar que se ha mantenido intacta la historia del lugar.

Eduardo Goilenberg (2002), representante de IRSA, claramente afirmaba que en términos económicos cuesta mucho más rehabilitar que hacer obra nueva, pero si la empresa encuentra una oportunidad,

\footnotetext{
8 "El Patio Bullrich actual conserva los valores de su antecesor, el antiguo edificio perteneciente a la familia Bullrich. [...] Así el pedigrí y la nobleza de sus productos se trasladaron también al espacio, convertido desde entonces en un lugar de encuentro, de novedad, de moda; atributos que se reproducen en el Patio actual" (Patio Bullrich 2001).
} 
la explota. Los centros comerciales que rehabilitan edificios históricos luego se apropian del valor cultural, histórico y simbólico que flota en el lugar: "[...] es un valor agregado que de otra manera no lo podés crear, porque necesitás historia atrás, que no todos los shopping lo tienen. Si lo tenés es mejor".

Este centro comercial desde sus orígenes, al igual que la mayoría de los emprendimientos que rehabilitan inmuebles históricos, ha intentado recuperar el valor simbólico que está cargado en el edificio y en su entorno, se lo ha apropiado, transformándose en un valor económico extra (monopólico) respecto a la actividad comercial en sí misma. Ubicado en una de las mejores zonas residenciales de la ciudad, dirigido a un público selecto social y económicamente que se siente identificado con los valores y símbolos que ha forjado este espacio urbano único y que ha sido todo un emblema diferenciador del Buenos Aires de fines del siglo XIX y principios del XX, todos estos elementos han logrado generar un espacio urbano con una fuerte identidad, un mito urbano.

\section{Conclusiones}

Más allá de la anécdota o de la nostalgia, el tratamiento de la ciudad debe partir de la constatación de un fenómeno: que la estructura espacial es el soporte material de un complejo sistema de relaciones sociales y que entre ambos términos (espacio y sociedad) existe una relación de mutuo condicionamiento que se desarrolla a lo largo de la historia, cuyo resultado es una identidad urbana y un espacio en el que podemos reconocer la impronta de una estructura social.

La transformación de la ciudad expresa un sistema de intereses (económicos-políticos), y a su vez un sistema de valores, de mitos, de anhelos colectivos de una sociedad, de la que se convierte en soporte, símbolo o contradicción. Con este marco podemos afirmar que la estructura urbana no solo contiene una función, sino que en muchos casos los espacios tienen un valor, simbólico, cultural como en este caso, como recuerdo o como aspiración de algo que alguna vez existió.

Las estrategias comerciales basadas en la nostalgia y la recuperación del pasado junto a la arquitectura hecha de citas y de revival tienden a anular en la escena urbana la distinción entre ayer y hoy, entre presente y pasado. Los centros comerciales que recuperan los valores sociohistóricos que están cargados en los propios edificios a ser rehabilitados, cumplen un doble propósito: por un lado preservan ciertas características localistas de tradición y conmemoración histórica, y por el otro, coexiste la dimensión global, entre otras, con la presencia de las grandes marcas nacionales e internacionales. Los centros comerciales necesitan tener estas marcas-logos para atraer consumidores y en el caso de Argentina, cuanto más internacionales sean, mas poder de atracción tendrán. En 
las entrevistas que hemos realizado sobre las motivaciones hacia los centros comerciales en la ciudad de Buenos Aires en el año 2010, una de las destacadas era "ir a un centro comercial a comprar marcas". El tipo de marcas, productos y precios determinará la diferencia entre los propios centros comerciales, o sea, cuanto más exclusivas sean y mayor valor posean, más exclusividad tendrá el centro comercial y sus consumidores. Este es el caso de Patio Bullrich: "Patio Bullrich, el lugar de Buenos Aires que las más exclusivas marcas internacionales eligieron para llegar a usted" (Shopping Bullrich s.d.).

La recuperación y re-creación del pasado, junto a un edificio emblemático y convocante y una propuesta comercial globalizada y exclusiva, orientada a un público también exclusivo, han gestado el mito del Patio Bullrich.

\section{Bibliografía}

ALTO PALERMO (1998): Alto Palermo Centros Comerciales. Reporte anual.

AMENDOLA, G. (2000): La ciudad Posmoderna. Madrid: Celeste ediciones.

ARQUIS (1996): Reforma y ampliación del Patio Bullrich, junio, núm. 9, pp. 39-41.

BLAKSLEY, S. (2011): "La industria de los shopping centers cumple 25 años", en IV Congreso internacional de shopping centers, 21-22 septiembre, Buenos Aires.

CASC (2012): Cámara Argentina de Shopping Centers.

CORNEJO PORTUGAL, I. (2007): El lugar de los encuentros. México: Universidad Iberoamericana.

- y BELLÓN CÁRDENAS, E. (2001): "Prácticas culturales de apropiación simbólica en el centro comercial Santa Fe". Revista Convergencia, enero-abril, año 8, núm. 24, pp. 67-86.

CUTOLO, Vicente (1996): Historia de los barrios de Buenos Aires, vol. 1. Buenos Aires: Elche.

DEL SOlAR, J. (1999): Retiro. Apuntes sobre la Historia de Buenos Aires. Buenos Aires: La Gaceta del Retiro.

ESCUDERO GOMEZ, L. (2008): Los centros comerciales. Espacios postmodernos de ocio y consumo. Cuenca: Universidad de Castilla La Mancha.

FEATHERSTONE, M. (2000): Cultura de consumo y posmodernismo. Buenos Aires: Amorrortu.

FERREIRA FREITAS, Ricardo (1996): Centres commerciaux: îles urbaines de la post-modernité. Paris: L'Harmattan.

FUNDACIÓN TEATRO COLON (s.d.): "Nuevo espacio de la Fundación Teatro Colón en Patio Bullrich". Gacetilla.

GALLET, Daniel (2010): Los Coleccionistas: pintura argentina [en línea]. En: www.loscoleccionistas.com/index2.html

GARCÍ́A BALLESTEROS, Aurora (1998): "Nuevos espacios del consumo y exclusión social". Anales de Geografía de la Universidad Complutense, núm. 18, pp. 47-63.

GARCÍA ESCALONA, E. (1997): "Espacio central y actividad comercial". Distribución y consumo, junio-julio, pp. 11-21. 
GOILENBERG, Eduardo (2002): Entrevista a Eduardo Goilenberg, Director de Nuevos Negocios de Alto Palermo-IRSA, por Silvana Sassano.

GONZÁLEZ, Mariana (2001): Entrevista a Mariana González, Coordinadora del Área Comercial Patio Bullrich, por Silvana Sassano.

GUÍA DE LA ARQUITECTURA DE BUENOS AIRES (1992): Itinerarios. Barrio Norte. Recoleta, núm. 31. Buenos Aires: Facultad de Arquitectura y Urbanismo, U.B.A.

LÓPEZ LEVI, L. (1999): Centros comerciales: Espacios que navegan entre la realidad y la ficción. México: Nuestro Tiempo.

MúJICA LAÍNEZ, M. (s.d.): La Casa Bullrich.

PATIO BULLRICH (1988): "Un verdadero clásico de la Ciudad de Buenos Aires". Tríptico Patio Bullrich.

- (1990): Informe, 22 de mayo de 1990, Las Vegas, Nevada.

- (1990b): "Un espacio recuperado para la ciudad". Tríptico Patio Bullrich, 22 de mayo.

- (2001): "Un lugar con historia". Tríptico Patio Bullrich.

- (2010): Encuesta a clientes del centro comercial.

SANTOS, Milton (1987): O espaco do cidadao. San Pablo: Libraria Nobel.

SARLO, Beatriz (2001): Escenas de la vida posmoderna. Buenos Aires: Ariel.

SASSANO LUIZ, S. (2001): "Transformación de un espacio urbano: El caso del Mercado de Abasto de Buenos Aires". Anales de geografía de la Universidad Complutense, núm. 21, pp. 99-118.

SCOBIE, J. (1977): Buenos Aires, del centro a los barrios. 1870-1910. Buenos Aires: Solar.

SHOPPING BULLRICH (s.d.): Patio Bullrich Buenos Aires [en línea]. En: www.shoppingbullrich.com.ar/ [Consulta: septiembre de 2012].

SOJA, Edward (1999): "Thirdspace: expanding the scope of the geographical imagination", en D. Massey, J. Allen y P. Sarre (eds.), Human geography today, pp. 260-278. Cambridge: Polity Press.

- (2008): Postmetrópolis. Madrid: Traficantes de sueños.

VOLPE, Aldo (2002): Entrevista a Aldo Volpe, arquitecto y representante del estudio de arquitectura de Juan Carlos López y Asociados por Silvana Sassano.

- (2007): Entrevista a Aldo Volpe, arquitecto y representante del estudio de arquitectura de Juan Carlos López y Asociados por Silvana Sassano.

\section{Fuentes hemerográficas}

La Nación Revista, "Si este es el Patio...", 29 de septiembre de 1988, pp. 32-34.

La Nación, "Moderna concepción de un espacio comercial", 17 de agosto de 1988, pp. 2-3.

La Nación, "Irsa se quedó con el Patio Bullrich", 16 de julio de 1998, Sección Economía, pp. 1 y 3.

La Nación, "Se amplía el Patio Bullrich", 14 de junio de 1995, p. 6.

La Razón, "El viejo Patio Bullrich fue convertido en nuevo y atractivo centro de compras", 16 de septiembre de 1988, p. 6.

La Nación, "Aires de renovación en el Patio Bullrich", 24 de agosto de 1988. 
La Nación, "Millonarias inversiones para otra manera de comprar", 14 de septiembre de 1988 , p. 12.

La Nación, "El primer gran paseo de compras dentro de los límites de la Capital", 17 de septiembre de 1988, p. 12.

La Nación, "Quedó inaugurado ayer el Patio Bullrich Shopping", 16 de septiembre de 1988.

La Prensa, "Celebrará la firma Adolfo Bullrich y Cía. Limitada S.A. el centenario de su fundación", 5 de abril de 1967.

Clarín, "La nueva ola de shoppings recuperará la inversión con varios años de crecimiento", 3 de octubre de 2010, Suplemento Economía. 